\title{
February 1835
}

/43r cont'd/ Sunday Feb ${ }^{y} 1^{s t}$.

Did not feel very well this morning - therefore did not go to the Hosp ${ }^{1}$. Went to the chapel in the R. du Bouloi to hear $\mathbf{M}^{\mathrm{r}}$. Newstead.

Monday $2^{\text {nd }}$.

Went to the H. St . Louis with Biett - some admirable cases of Ichthyose, Erythéme Papulatum, Pityriasis versicolor, Favus ${ }^{1}$ on the legs \& Impetigo Figurata. A person also exhibited a remarkable example of Paralysis Agitans ${ }^{2}$ of the whole right side of the body, which Biett supposed to arise from disease in the opposite side of the brain.

Tuesday $3^{\text {rd }}$.

Went to the Hop ${ }^{1}$. du Midi. Saw Ricord apply some strong Hydrochloric Acid to the gums in a case of salivation. ${ }^{3} \mathrm{He}$ stated, that so far $/ 43 \mathrm{v} /$ from considering ptyalism necessary in Vener ${ }^{1}$. disease, he thot ${ }^{t}$ it generally injurious. The method by which he introduces Mercury into the system is the following - he washes the part with a solution of Chloride of Lime \& sprinkles Calomel on it. Decomposition takes place, \& a mild corrosive sublimate is produced. M. R. remained but a very short time in his men's ward. I therefore left him \& went to La Pitié to hear Louis lecture. I do not like him so well as Chomel. At Ribail's had two bandages - one for fractured olecranon ${ }^{4} \&$ another for fract ${ }^{r}$. of Radius - the latter Dupuytren's - former not of much value. At Sichel's several cases but none particular.

Wednesday $4^{\text {th }}$.

Went this morning to $S^{t}$. Louis - Lugol went round but made no observation. He opened a large abscess on the outer \& upper part of the thigh $\&$ injected the sac with a solution

\footnotetext{
${ }^{1}$ Favus: a contagious disease of the skin characterised by pustules containing considerable viscid material. These dry to form honeycomb-like scabs. (Hooper, Lexicon, p. 571.)

${ }^{2}$ Paralysis agitans: the general condition of paralysis was called palsy, in which there was a loss or diminution of the power of voluntary motion affecting any part of the body. The most usual form of palsy was when one side of the body was affected, but it could affect both legs or arms or one side of the face. In the present case of shaking palsy (Parkinson's disease, today), there was a feeble trembling action of the muscles which did not actually amount to palsy but was, similarly, an affliction of the nervous system. (Hooper, Lexicon, pp. 934-5.)

${ }^{3}$ Salivation or ptyalism involves an increased flow of saliva from the mouth. Whilst it was a symptom associated with the administration of mercury as a therapy for venereal conditions, it could also be a symptom of many diseases of the mouth and neighbouring parts. Hydrochloric acid was used in the treatment of ulceration in the mouth, the region apparently affected in this case. Ricord, in his exposition in the hospital, had moved on to the phenomenon of ptyalism associated with the treatment of venereal diseases to emphasise his disagreement with it as an appropriate therapy in all cases of syphilis. Ricord had been influenced by the work of Richard Carmichael (1779-1849), an eminent Irish surgeon whose reputation was based on his researches on venereal diseases. Carmichael demonstrated the difference between "syphilitic affections", characterised by chancre, which should be treated with mercury, and other forms of the disease not requiring mercurial treatment. (Warren, Parisian education, p. 215.)

4 Olecranon: elbow.
} 
containing a few drops of Iodine. At M. Alibert's we were shown two cases of Peliosis or Purpura - one very good one of Lepra Communis ${ }^{5} \&$ another of ------- or Sycosis nearly cured. At Ribail's we went over the bandage for fract ${ }^{d}$. condyles. ${ }^{6}$ At Sichel's there was an excellent case of ophthalmia neonatorum quite cured.

Thursday $5^{\text {th }}$.

Went down to Hotel Dieu to Breschet's. Saw a case of Strumous Ophthalmia there without any Photophobia ${ }^{7}$ - very distinctly marked Plyctenula. ${ }^{8}$ Case of Erysipelas faciei there treating very badly. Not nearly active enough. Ribail lectured today on the splints of the leg \& arm - particularly Scultet's apparatus. At Sichel's several very good cases. Went down to the Hotel Dieu \& agreed to take a course of Diagnosis with the stethoscope, Percussion \&c. of M. Roquet, Interne ${ }^{9}$ de M. Récamier - at 15 francs par mois. Drank tea again at $\mathbf{M}^{\mathrm{r}}$. Newstead's with a party.

Friday $6^{\text {th }}$.

Went to the Hotel Dieu to the course of Diagnosis at 7 A.M. Lecture on general principles, method of questioning patients, examining countenance \&c. ${ }^{10}$ Sanson did not lecture today. I don't know for what reason. Went round $/ 44 \mathrm{r} /$ with Breschet. Erysipelas no better - ordered a bleeding. Erysipelas is very common in Paris - they employ very much the Medecine Expectorante, ${ }^{11}$ so if a case is at all severe, the pat ${ }^{\mathrm{t}}$. dies almost certainly. Amongst the outpat $^{\text {ts }}$. was one with fracture of the jaw of 2 months standing. There was deformity \& preternatural motion - but not crepitus, because I presume a false joint was formed. He was admitted. An excellent case at Sichel's of complete cure of Keratitis [and] Iritis with abscess between layers of cornea $\&$ subsequent hypopion, ${ }^{12}$ - only slight "tache" remaining.

Saturday $7^{\text {th }}$.

Went to Roquet's course of Diagnosis. Did not feel well \& therefore did not remain to Breschet's - understand he had good case of luxation of the humerus - called on Bird \& then went over to Rue Neuve des Augustins. ${ }^{13}$

\footnotetext{
${ }^{5}$ Lepra communis was an alternative name for Lepra vulgaris, see November 10, note 113.

${ }^{6}$ The condyle is the head of the humerus bone of the upper arm.

${ }^{7}$ Photophobia: intolerance to light.

${ }^{8}$ The correct spelling is phlyctenula or phlyctena. The condition consists of an inflammatory vesicle, pimple or blister on the conjunctiva or cornea of the eye. In Larousse médical there is an illustration of it referred to as Phlyctène conjunctivale (p. 792).

${ }^{9}$ This is the only occasion on which an interne is specifically named and this reference confirms that the internes did hold their own private courses - in this case on percussion - for which they were paid.

${ }^{10}$ The diarist would have been familiar with this procedure of taking a patient's medical history through careful observation because it was part of the Edinburgh curriculum. (See Introduction, pp. 16.)

${ }^{11}$ Médecine expectorante: expectorants were medicines to promote expectoration of phlegm in bronchial conditions. They could be nauseating, stimulating, antispasmodic or irritating in nature.

12 "Hypopion" is the French spelling; "hypopyum" the English. Glutinous yellow pus-like fluid accumulating in the anterior chamber of the eye occurring in severe, acute inflammation. (Hooper, Lexicon, pp. 703-4.)

${ }^{13}$ The diarist probably meant rue Neuve-Saint-Augustin, the location of one of the churches he attended. He repeatedly gets the name wrong. (Hillairet, Rues de Paris, vol. 2, pp. 383-4.)
} 
Sunday $8^{\text {th }}$.

Did not go to any hospital this morning. Went to the Chapel in the R. de Bouloi \& remained to $^{14}$ the Sacrament - this is the first time I have ever been a participator in it $\&$ was very glad to have an opportunity.

Monday $9^{\text {th }}$.

Went to the Hotel Dieu to M. Roquet's course, heard aegophony ${ }^{15}$ excellently in a case of effusion into the sac of the pleura in one part exactly like the sound of a person speaking thro' a comb. I never heard anything so characteristic - all the rational signs of effusion were present at the same time. Went to the $H$. $S^{t}$. Louis - no very good pat ${ }^{\text {ts }}$. except a case of psoriasis complicated with itch. The latter was not very well marked, but I think I sh ${ }^{d}$. have detected it. Came back to Ribail - he lectured on fractures of the leg. At Sichel's there was a stranger today - it appears that $S$. is gone out of town \& has left this Gent ${ }^{n}$. in charge of his pat $^{\text {ts }}$. in the meantime. I rather like him than otherwise, he gets over the pat ${ }^{\text {ts }}$. very quickly he does his work in half the time, which Sichel takes.

\section{/44v/ Tuesday $10^{\text {th }}$.}

Went down to the Hotel Dieu this morning to the course of M. Roquet - he desired us hereafter to come only thrice a week $\&$ the course will continue for two months. As it occupies too much of the day - I think this is rather an improvement than otherwise. Heard a most extraordinary sound today, which $\mathrm{M}$. Hurtoloup ${ }^{16}$ declared he had never listened to before - it was like the grating of a cartwheel. The symptoms generally were those of pulmonary apoplexy. ${ }^{17}$ Went at 11 to see Dupuytren's funeral ${ }^{18}$ - it was very numerously attended by students, all the Professors \& variety of "Non professionals". He was buried in Père la Chaise ${ }^{19}$ - did not follow the cavalcade but took a walk in the Boulevards.

\footnotetext{
${ }^{14}$ Another example of the diarist's franglais.

${ }^{15}$ Aegophony: a peculiar nasal bleating or trembling character of the patient's voice heard on pectoral auscultation at the upper border of some diseased states with pleural effusions (flow of fluid) from the lungs in cases such as pleurisy. To some the sound resembles the bleating of a goat.

${ }^{16}$ The individual's name was actually spelt Heurteloup. He was Charles Louis Stanislas Heurteloup (1793-1864), a specialist in lithotrity, for which he devised a beak-like instrument in 1832 for pulverising bladder stones without the need to perforate the bladder. (Warren, Parisian education, p. 152.)

${ }^{17}$ Pulmonary apoplexy: this form of apoplexy, a sudden loss in some degree of the powers of sense and motion, can result from the action of suffocating exhalations. (Hooper, Lexicon, pp. 146-7.) See also November 21 , note 182.

${ }^{18}$ Dupuytren had carried out the greater portion of the surgical care of patients in the Hôtel Dieu, the other two surgeons working with him being Sanson and Breschet. Dupuytren was described as having performed his work, which included daily visits night and morning, free consultations, surgical operations and clinical lectures "with a zeal and assiduity difficult to imagine". (Ratier, Medical guide to Paris, p. 21.)

${ }^{19}$ Père La Chaise was from 1804 the principal cemetery of Paris of almost a hundred acres, situated on rising ground with extensive views to the north-east of the city. The cemetery was appropriated for the interment of the inhabitants of the 5th, 6th, 7th, 8th and 9th arrondissements, and the poor were buried free close to each other in plots reopened every five years. However, purchase of perpetual plots for 125 francs per square metre, rather than the temporary plots for 50 francs per five years, enabled inhabitants from any part of the capital to be buried there. Thus many distinguished individuals chose this as their place of interment, and grand monuments were erected to them. (Galignani's new Paris guide, pp. 597-613.)
} 


\section{1-13 February 1835}

Wednesday $11^{\text {th }}$.

Went down to Breschet's ward this morning - nothing particular there. The case of Erysipelas faciei was much better. There is also a bad case of bruise followed by Erysipelas of the leg \& some little sloughing. The treatment is the constant application of cold water. Went down to the Dead Room - the Interne was examining the body of a female who died of Puerperal fever. ${ }^{20}$ The subperitoneal cellular tissue was filled with pus - the lymphatic vessels ${ }^{21} \&$ glands also - in the peritoneal cavity was an effusion of brown flocculent fluid - the peritoneum in some parts particularly in the right hypochond: ${ }^{22}$ was covered with a false membrane. The uterus internally was lined with a nasty brown col $^{\mathrm{d}}$. coat $\&$ at the anterior were flocculi being the "debris" of the placenta. The veins were much engorged with a remarkably black grumous ${ }^{23}$ blood. There was another examination of a person who died of an enormous carbuncle ${ }^{24}$ in the back. Some very good cases at Sichel's today, partic-/45r/ularly of Pannus, which the Physician talked of treating by means of solid caustic applied around the margin of the cornea, so as to destroy the vessels going to it. He spoke also of ulcers of the cornea after variola. These, he said, $s^{d}{ }^{d}$. be treated by means of caustic applied in subst ${ }^{\mathrm{e}} .{ }^{25}$ if the eye $\mathrm{c}^{\text {ld }}$. be opened if not, in strong solution 3 gr to $\xi \mathrm{i}$. In rheumatic ophthalmia he stated that he considered warm very superior to cold applications.

Thursday $12^{\text {th }}$.

Went down to the Hotel Dieu. Breschet not come. In the dead room an examinat ${ }^{n}$.of a person who died with Typhoid symptoms - in whom the lung was in the state of grey hepatization \& tubercular infiltration - one or two small cavities. Breschet came late \& hurried very rapidly thro' his wards. Nothing particular at Ribail's or Sichel's.

Friday $13^{\text {th }}$.

Went to Roquet's course at Hotel Dieu - saw case of spontaneous gangrene in a woman aet 45 produced apparently by inflam ${ }^{n}$. of the popliteal artery on either side. Case of Pulmonary Apoplexy much the same. Heard the "bruit" of the foetal heart today. Sanson had several operations - first, extraction of a sequestrum ${ }^{26}$ from the tibia - removal of a fatty tumor from

\footnotetext{
${ }^{20}$ Puerperal fever was often called child-bed fever because it followed soon after delivery, generally about the third day. It usually began with a severe febrile condition, tenseness and tenderness of the abdomen, great pain, laboured breathing and frequently attacks of rigor. Death, as in this case, was not an uncommon outcome and on dissection widespread inflammation of the internal organs was revealed. Treatment included bleeding if the patient was not too weak. Hot fomentations and cordial confections together with brandy or diluted wine were also tried. (Hooper, Lexicon, pp. 1031-2.)

${ }^{21}$ The lymphatic vessels were considered to be small transparent vessels originating in every part of the body, carrying a transparent fluid, lymph or chyle. With the lacteal vessels of the intestines, they were seen to form what was termed the absorbent system. (Hooper, Lexicon, p. 748.)

${ }^{22}$ Hypochond: hypochondrium, the upper lateral regions of the abdomen which lie beneath the false ribs.

${ }^{23}$ Grumous: thick, clotted, viscid material.

${ }^{24}$ Carbuncle: hard, circumscribed, inflammatory, boil-like tumour that sometimes forms on the cheek, neck or back and which soon develops a dark core. It then discharges a foetid material. It was treated with poultices and lanced if necessary. (Hooper, Lexicon, p. 129.)

${ }^{25}$ In subst ${ }^{\mathrm{e}}$ : in solid form.

${ }^{26}$ Sequestrum: detached piece of bone lying within a cavity formed by necrosis. Also applied to a portion of skin separated by disease from the surrounding parts.
} 


\section{3-16 February 1835}

the axilla, ${ }^{27}$ amputation of the finger $\&$ radical cure ${ }^{28}$ of Hydrocele. ${ }^{29}$ Chomel gave us a good lecture - Typhus fever, he said, was more prevalent now than it had ever been before. At Sichel's there was a pat ${ }^{t}$. with an oblique pupil from without downwards \& inwards. This is opposed to the opinion of the Germans. They say in Rheumatic Iritis the pupil is oblong from above downwards or vertically - in Arthritic transversally - in Syphilitic diagonal from above downwards \& outwards. What was this? Bird called this Evening.

Saturday $14^{\text {th }}$.

Did not go to any hospital, remained at home to read. Afterwards went to the Foreign Reading Room to see the English Reviews. Dissected in the Evening.

Sunday $15^{\text {th }}$.

Went to the Chapel in the R. de Bouloi.

Monday $16^{\text {th }}$.

Attended Roquet's visit - nothing very particular, except a case of Delirium Tremens. ${ }^{30}$ Saw Sanson operate today - amputation of the thigh, by circular incision. He did it tolerably well. $145 \mathrm{v} /$ Chomel lectured on perforation of the intestine - of which he has a case at present in the wards - at least he thinks such is the case. The pat ${ }^{\mathrm{t}}$. had been complaining for some time past, but two days ago, she was seized with an exceedingly violent pain in the abdomen, which cont ${ }^{\mathrm{d}}$. during the whole night so as entirely to prevent sleep - \& to produce constant moaning. He had employed leeches plentifully - but beyond that he did not mention the treatment he intended to pursue. Why not try Opium according to Graves' method ${ }^{31}$ surely it is worth trying. Saw Breschet today apply a new kind of actual cautery, ${ }^{32}$ superior I think, to that most frequently in use. He had two inst ${ }^{\text {ts }}$. formed like hammers $T$ with a long wooden

${ }^{27}$ Axilla: the armpit, which contains a number of lymph nodes.

${ }^{28}$ Radical cure: Warren describes having seen Dupuytren operate for radical cure of hydrocele. Following the current practice, he punctured the sac surrounding the hydrocele allowing the liquid to drain out. He then stuffed the wound with lint to prevent a refilling and to promote the formation of scar tissue. According to Warren, Dupuytren packed too much lint into the wound "stuffing it tight like a football", which provoked haemorrhage and suppuration, delaying and doubling the usual healing time. (Warren, Parisian education, p. 96.)

${ }^{29}$ Hydrocele: the collection of serous fluid between two membranes, for example, of the tunicae vaginalis testis of the testicle or spermatic cord. (Hooper, Lexicon, pp. 683-4.)

${ }^{30}$ Delirium Tremens: a species of delirium induced by excessive indulgence in alcoholic liquors and characterised by tremblings and various delusions of the senses. The term was introduced by Dr Thomas Sutton in 1813 to describe a form of delirium rendered worse by bleeding but improved by opium (see Sutton, Tracts on delirium tremens).

${ }^{31}$ Graves' method: Robert Graves (1763-1849) had a prescription for opium purificatum to be taken in pill form and for tinctura opii to be taken internally. He also provided a prescription and directions for the preparation of a soapy tincture with opium (Tinctura saponis cum opio) which included the instruction to "Digest the opium and soap in the spirit, three days; then to the strained liquor add camphor and oil, diligently shaking the vessel". Graves provided a table showing doses appropriate to age and took as the adult standard, "one of twentyone years of age".

${ }^{32}$ Cautery: an instrument for destroying tissue by burning and described as actual when white-hot and ready for use. (A potential cautery, used for the same purpose, was a substance such as kali purum or potash listed in former dispensatories or pharmacopoeias). Cauteries were formerly the only means of preventing haemorrhage from divided arteries, during surgery for instance, until the introduction of ligatures. (Hooper, Lexicon, p. 341.) 


\section{6-17 February 1835}

handle \& iron head. He dipped them into water kept at a boiling temp ${ }^{r}$. applied one to the part to be cauterized for a few seconds - then took it off $\&$ applied the other $\&$ so cont ${ }^{\mathrm{d}}$. till he had surrounded the whole joint, the knee. This is decidedly superior to the common actual cautery because it has not so terrific an appearance. At the Consultat ${ }^{n}$.Gratuit there was a pat ${ }^{t}$. who had broken the ulna by a fall - the accident was qu easily recognised by making an attempt at pronation $^{33}$-crepitus being distinctly felt in the situation of the fracture. A woman entered the Salle $S^{t}$. Come ${ }^{34}$ with a very deep contused wound ${ }^{35}$ on the right leg, just below the calf. A carriage knocked her down \& passed over this spot. The soft parts were cut down to the bone \& much bruised. M. B. advised her to have it amputated, but to this she $w^{\text {ld }}$. not consent - he therefore ordered cold applications. At Ribail's M. Boyer's splint for fracture of the neck of the thigh bone ${ }^{36} \&$ Dupuytren's double inclined plane made with cushions - latter much superior to the former. At Sichel's nothing. Went to Broussais' lecture for the first time for many months-must attend regularly now, or I shall lose my certificate. By the bye heard from Clifton yesterday - my father seems to wish me to pass in London, immed ${ }^{\text {ly }}$. after getting through in $\mathrm{Ed}^{\mathrm{n}}$. I shall have no particular objection, if it be necessary. I fear from his letter that I shall not be able to spend next winter in London /46r/ as I had made up my mind to do.

Tuesday $17^{\text {th }}$.

Went to the H. Dieu - was not sure whether Roquet expected us or not. He was not in his ward, so followed M. Sanson. I learn nothing ever from this man - it is really almost time thrown away. ${ }^{37}$ Saw dissection of case of Recamier's ${ }^{38}$ - Scirrhus Pylorus, ${ }^{39}$ in which there had been no vomiss. ${ }^{40}$ - I suppose, because the passage was not entirely obstructed. A most remarkable appearance presented itself in the seat of the coeliac axis - a round osseus ${ }^{41}$ tumor, thro' which the coeliac artery ${ }^{42}$ passed before it divided. Surely this must be an

\footnotetext{
${ }^{33}$ Pronation: the act of turning the palm of the hand downwards. It is performed by rotating the radius upon the ulna, by means of several muscles, which are termed pronators.

${ }^{34}$ The ward of St. Come was one of the twenty-three in the Hôtel Dieu and, like eleven others, was devoted to women patients. It contained forty-two beds. (Ratier, Medical guide to Paris, pp. 16-17.)

${ }^{35}$ Contused wound: a wound with bruising.

${ }^{36}$ Fracture of the neck of the femur. This is extensively dealt with in Alexis Boyer, Traité des maladies chirurgicales, vol. 3, pp. 258-324. Illustrations of Boyer's splints, including the mechanism for producing continuous extension whilst the limb was splinted and the straps for holding the limb in place, are also provided (pp. 640-1).

${ }^{37}$ The diarist is highly critical of Sanson who was, nevertheless, a valued member of the successful surgical team under Dupuytren and alongside Breschet. They were very science-oriented and, for example, if various methods of treatment were proposed for the same disease, each would use a different one and then compare their results. Thus in the operation for stone Dupuytren operated by the bi-lateral, Breschet by the ordinary lateral and Sanson by the recto-vesical method. (Ratier, Medical guide to Paris, p. 25.)

${ }^{38}$ Joseph Claude Anthelm Récamier (1774-1852), a highly regarded practitioner and professor of clinical medicine at the then newly organised (post Revolution) School of Medicine, was in 1828 engaged in research on the treatment of cancer by means of compression. He was renowned for the sagacity with which he recognised diseases. He believed that cancer was initially a local infection which became a general infection only when the products of degeneration, taken up by absorbents, were carried into the circulating system. (Ratier, Medical guide to Paris, pp. 25-6.)

${ }^{39}$ Scirrhus Pylorus: a hard tumour of the pyloric region - that part of the stomach which opens into the intestines.

${ }^{40}$ Vomiss: a contraction for the French term vomissement - vomiting.

${ }^{41}$ Osseus: a mis-spelling of "osseous" meaning boney.

${ }^{42}$ Coeliac artery: this is the first artery given off from the aorta in the abdomen. It sends branches to the diaphragm, stomach, liver, pylorus, duodenum and spleen.
} 
aneurism ossified. Waited some time for Breschet, but as he did not come - I walked home after having looked at the woman with contused wound - she said it was quite well, \& in very good spirits, rejoicing much in having refused the operation. M. Ribail lectured today on M. Mayor's method of treating fractures - very ingenious certainly \& many, I dare say, good, but the majority appeared to me inferior to the ordinary means. Went to the Theatre Français. A piece of Moliére's was the attraction - his best comedy, I believe, "Le Bourgeois Gentilhomme" appeared in it, as well as in a little farce "La Suite du Balle Masqué". She did not appear to such advantage as the last time I was at the theatre but her voice is extremely sweet $\&$ her smile enchanting.

Wednesday $18^{\text {th }}$.

Went to the Hotel Dieu to Chomel's - the pat ${ }^{\mathrm{t}}$. with Peritonitis is not yet dead, but no hopes of recovery. There is a case of quotidian ague ${ }^{44}$ in the wards but not pure sometimes one, sometimes two fits recurring in the same day. M. C. administered Quinine, but said, from the fever being somewhat irregular, he had not so much expectation of benefit arising from its administration, as if the disease were pure. M. Ribail commenced dislocations today - those of clavicle \& humerus. Broussais was on Catalepsy \& Animal Magnetism, ${ }^{45}$ in the latter he was a firm believer. Andral gave us a most excellent lecture on pneumonia.

146v/ Thursday $19^{\text {th }}$.

Went down to the Hotel Dieu to Recamier's ward - heard aegophony very distinctly, râle sibilant \&c. Case of contused wound in Breschet's ward better - heard Louis lecture on Emphysema ${ }^{46}$ of the lung - a subject very well treated. Ribail continued on dislocat ${ }^{\mathrm{n}}$.of the upper extremity. Went to Gerdy $-c^{\text {ld }}$. not hear him, therefore ret ${ }^{d}$. home. This is the day for the Election of Speaker of the H. of Commons. ${ }^{47}$

\footnotetext{
${ }^{43}$ Molière, Le bourgeois gentilhomme, Paris, 1670. First performed before King Louis XIV at Chambort in 1670, it greatly amused the court and became the most famous of all comedy ballets.

${ }^{44}$ Quotidian ague: an intermittent fever whose paroxysms were interspersed by periods of normal termperature of about twenty-four hours. See November 4, note 56.

${ }^{45}$ Animal Magnetism: a sympathy was held, by some, to exist between the magnet and the human body, by means of which the magnet could cure many diseases in an unknown manner. But Hooper declared in his 1831 Lexicon, “Animal magnetism is now entirely exploded" (p. 798).

${ }^{46}$ Emphysema: or pneumatosis. This was also known colloquially as "windy swelling", because the air in a particular tissue causes swelling, in this case in the lungs, where it gives rise to a crackling noise and much difficulty in breathing, leading in some cases to a feeling of oppression and anxiety. This condition was one of Louis's research specialties. (Hooper, Lexicon, p. 987.)

${ }^{47}$ Despite the 1830 s and 1840 s being seen by some as "the age of Peel", his Tory Party did suffer defeats during the 1830 s, which saw several changes of government between the Whigs and Tories. These changes involved controversies over the major Reform Act of 1832 and the issue of Catholic emancipation to which the diarist refers from time to time. The Duke of Wellington had briefly taken over from the Whig Viscount Melbourne as head of a caretaker administration in November 1834 to be replaced by Sir Robert Peel in December. The Tory party was anything but united, as indicated by this late appointment of the Speaker in the House of Commons, and Peel himself would be replaced two months later on Melbourne's return for a six-year term in office in April 1835. (Evans, Modern state, pp. 306-19.)
} 
Friday $20^{\text {th }}$.

Went to Chomel's - he lect ${ }^{\mathrm{d}}$. on a case of typhus fever, fatal from phlebitis after bleeding there were no marks of affection of the glands of Peyer. ${ }^{48}$ This is the first case of the kind, which Chomel has met with in the last $4 y^{\text {rs }}$. - he does not consider this absence to prove that the case was not one of Typhus. He firmly believes it to have been such, the glandular affection he imagines to be always secondary. Went to Clamart today to dissect the muscles $\&$ fasciae $^{49}$ of the abdomen. Heard Broussais on Convuls ${ }^{\text {ns }}$. \& some other diseases all which he thot ${ }^{t}$ to arise from Gastro Enteritis. Andral was on the causes $\&$ signs of pneumonia - an excellent lecture.

\section{Saturday $21^{s t}$.}

Went to Roquet, he pretends, now, that we must pay him for the subjects independent of the 20/-. ${ }^{50}$ I sh ${ }^{\mathrm{d}}$. like therefore much to know for what we pay the 20/-. If he will not take us on these terms, we will leave him. Paid Madame Lecomte for a month's lodging \& boarding due yesterday - \& gave her notice, that $I s^{d}$. quit in a month. She seemed a good deal annoyed at it. Gerdy was on vesico vaginal \& recto vesical fistulae. ${ }^{51}$ I don't like him at all.

Sunday $22^{\text {nd }}$.

Went to the R. De Bouloi this morning - good service. No letters at the Poste Restante.

Monday $23^{\text {rd }}$.

Went to the H. Dieu to Chomel's wards. Afterwards into Sanson's lecture, he was on fracture of the lower end of the fibula \& Dupuytren's apparatus. Chomel lectured on a case of Angina Pectoris ${ }^{52}$ - he said he did not know what the disease really was, but in the two last cases, he has examined, there was considerable dilatation of the two ventricules. ${ }^{53}$ He afterwards spoke of a case of pneumonia which was rather extraordinary - the sputa ${ }^{54}$ were characteristic $/ 47 \mathrm{r} /$ but not the stethoscopic symptoms ${ }^{55} \&$ the pulse was only 56 , however thinking it pneumonia, he had the pat ${ }^{\mathrm{t}}$. treated antiphlogistically. This morning he is much better \& the pulse has fallen to 40 , so that it $\mathrm{wl}^{\mathrm{d}}$. appear to be some idiosyncracy in the person's constitution. Went to call on Roqet [sic], ${ }^{56}$ but not being at home, left a note for

\footnotetext{
${ }^{48}$ An alternative name for typhoid fever, thought to be a variety of typhus, was Peyerian fever. It involved the enlargement and necrosis of the intestinal Peyer's patches or glands. (See also March 16, note 31.)

${ }^{49}$ Fasciae: the tendinous expansions of muscles which bind parts together.

${ }^{50}$ The text suggests that the diarist was paying Roquet in sterling. The $20 \mathrm{~s}$. (or $£ 1$ ) equalled 24 francs.

${ }^{51}$ Fistulae: ulcers with no disposition to heal (see January 9, note 48). Here, in one patient the fistula involved the vagina, and in the other, the rectum being connected to the bladder.

${ }^{52}$ Angina Pectoris: the name given to a disease first described by William Heberden in 1768 and so called from the seat of the disease - viz. the chest - and the sense of strangulation and anxiety which accompany this disorder of the heart.

${ }^{53}$ The diarist meant to write ventricles, from the Latin ventriculus - stomach or hollow membraneous sac. The ventricles referred to here are the cavities of the heart rather than those of the brain.

${ }^{54}$ Sputa: expectorant material from the lungs, which, as in this case, may be characteristic of some diseases such as pneumonia.

${ }^{55}$ Those symptoms, a range of sounds, obtained through use of the stethoscope.

${ }^{56}$ The diarist seems to be referring to the dispute with Roquet on Saturday 21 st, concerning the cost of the subjects for dissection.
} 


\section{3-24 February 1835}

him, declining his terms for dissection. I tho ${ }^{t}$. he was somewhat better than the majority of Frenchmen, but I find they are all alike - their sole business \& delight seem to consist in taking in or endeavouring to take in the raw "Englishers". Ribail gave us a lecture on "Nothing". Broussais lectured on, I scarcely know what - all I know is that he commenced with something about the brain, then with Angina Pectoris - raved about everything depending on Gastroenterite, ${ }^{57}$ railed against the opposers of the Physiologico Pathological school $^{58}$ \& concluded by most emphatically \& logically declaring that his opinions must \& $\mathrm{sh}^{\mathrm{d}}$. be correct. Andral terminated the subject of pneumonia today in a most admirable \& eloquent lecture $1 \frac{1}{2}$ hour long. The sheet anchor in the treatment, he declared was general bleeding $\&$ as to the use of antimon ${ }^{\text {ls }} .{ }^{59}$ he had not much faith in them.

Tuesday $24^{\text {th }}$.

Went to Roquet's class as usual at the H. Dieu. The man with pulmonary apoplexy is very ill - he has thrown up nearly $\xi \mathrm{xii}^{60}$ of pure blood. His face has altered very much since admission into the $\mathrm{H}$. It has become very thin and sharp \& of course he is much weakened. The peculiar sound on the left side is now gone $\&$ in its place is a loud gargouillement - of course a large cavity in that spot. It will be an exceedingly interesting examination if the man die, as appears most probable at present. He was bled last night $\&$ the blood is very buffed $\&$ cupped - the "cournne" ${ }^{11}$ being more than a $1 / 4$ of an inch thick $\&$ tough. I have not been able to detect any disease of the heart, but I suppose there is some hypertrophy of the right side. Louis lectured on a very interesting /47v/ case of chest disease - there was pleuritis with effusion on the left side $\&$ on the right pleuroperipneumony $-I c^{\text {ld }}$. not help being struck this morning with the idea, how very advantageous it $w^{\text {ld }}$. be to a med ${ }^{1}$. man in practice to take notes of his particular cases \& reason upon them on paper, as tho' he were giving a Clin ${ }^{1}$. lecture to his class. Many valuable cases, which pass under the observation of a practising Physician unimproved $\mathrm{w}^{\text {ld }}$. thus prove of inestimable advantage to him - it is not so much the recollection of these individual cases (tho' even that probably $\mathrm{w}^{\text {ld }}$. alone cause an ample remuneration for the time bestowed upon it) but the habit of reasoning, which is invaluable to a medical man, the only thing indeed which renders him clear headed $\&$ capable of acting on the spur of the moment. ${ }^{62}$ Louis appears to possess this habit

\footnotetext{
${ }^{57}$ As already noted, this was Broussais's "grand" explanation of the basis of all disorders, that is inflammation of the lining of the stomach (see November 7, note 82).

${ }^{58}$ By 1835 Broussais's reputation was in decline and his main doctrine of physiological pathology had lost its former momentum, having been challenged by younger contemporaries such as Andral and Chomel who espoused an anatomic-pathological orientation. It would have been against this doctrine that Broussais was railing. (Ackerknecht, Paris Hospital, pp. 61-80.) Whilst the diarist's father, if also a medical man, would have felt more comfortable with an emphasis on an anatomical approach to pathology, the son would have received a more scientific physiologically oriented medical education in Edinburgh.

${ }^{59}$ Antimonials were preparations in which antimony was the chief ingredient, see November 1 , note 5.

${ }^{60}$ This amounted to 12 apothecary ounces of blood.

${ }^{61}$ The blood removed from a vein during bleeding separates spontaneously into two parts - the transparent serum and the more solid brownish cruor or clot, which sinks. Sometimes a thin layer forms at the top of the serum which is called the buff, rind, crust or, as the diarist meant to write here "couronne" of the blood. (Hooper, Lexicon, p. 251.)

${ }^{62}$ The diarist is displaying a genuine interest in a systematic and scientific approach to his future professional responsibility as a doctor. He appreciates the value of sound observation and the importance of gathering reliable evidence on which to evaluate and improve his practice. He may even be expressing an interest in being
} 


\section{4-26 February 1835}

to a surprizing extent $\&$ therefore makes an excellent Clin 1 . Lecturer. Roquet agreed to release us from our "parole". ${ }^{63}$ Ribail lectured on nothing of any consequence. Returned home to read for a few hours before dinner - in the Evening, was engaged to a party at $\mathbf{M}^{\mathrm{r}}$. Newstead's. Spent an exceedingly agreeable Evening there. I am more \& more delighted every time I go to his house - there is something so sociable \& friendly about them. There was a Gent ${ }^{n}$. there from Cambridge, who contributed not a little to the amusement of the company.

Wednesday $25^{\text {th }}$.

Went down to Chomel's this morning. He lectured on a case of cancerous diathesis, ${ }^{64}$ in which there was scirrhus of the liver, stomach, bladder \& rectum, accompanied with so much dropsy that during life no tumor $\mathrm{c}^{\text {ld }}$. be perceived. At Ribail's, an hour thrown away on bleeding - Broussais on Asthma ${ }^{65}$ - Andral eloquent, as usual on pulmonary emphysema \& Apoplexy of lungs.

Thursday $26^{\text {th }}$.

Went to Roquet at H. Dieu - had some good cases of pneumonia, chronic bronchitis \& disease of the heart. In the dead room was an extraordinary case - during life, the intelligence was $/ 48 \mathrm{r} /$ perfect \& no sign of cephalic disease existed, except occasionally headache, but after death - we found an innumerable number of small abscesses in the brain, each situated in the convolutions \& surrounded by a firm membrane, enclosing the pus, so that they were truly encysted. The cerebral matter was healthy in their neighbourhood. In the right hemisphere a very remarkable appearance presented itself - in the posterior lobe was an enormous abscess extending superiorly over the lateral ventricle, inferiorly under it even into the anterior lobe, where it terminated in a cavity containing a black grumous fluid, the other portion of the abscess being filled with true pus. The walls of this "epanchement" ${ }^{66}$ were formed of cerebral matter in a state of ramolissement. ${ }^{67}$ Lateral ventricles, corpora striata \& optic thalami of either side, as well as the cerebellum healthy. ${ }^{68}$ Ribail was today on the application of cupping. He showed two or three convenient measures of applying the glass ${ }^{69}$ - one by placing one of the wicks, used in floating lamps lighted on the part \& covering it with the glass - another was to drop place a few drops of ether in the glass, set fire to it $\&$ immed $^{\text {ly }}$. apply to the part, before the edge of the glass has become

\footnotetext{
involved in medical education himself. Marshall Hall, an Edinburgh predecessor of the diarist, certainly held his Edinburgh education and training in high esteem.

${ }^{63}$ Presumably the dissection subjects did not now have to incur an additional charge.

${ }^{64}$ Diathesis: a constitutional disposition of the body, which, in this case, would seem to have been widespread cancer.

${ }^{65}$ Asthma was then a disease more common in later than in early life; it could become habitual and seemed sometimes to be hereditary. It affected all temperaments but most particularly the melancholic. A number of varieties of asthma were recognised. Treatments, which were largely directed towards the paroxysm of the attack, included purging, sedatives, antispasmodics, gums and a range of inhalants. Some of these, like bleeding, were not always beneficial. (Hooper, Lexicon, pp. 187-95.)

${ }^{66}$ Épanchement is the French term for an effusion, the escape of any fluid and its accumulation in another cavity.

${ }^{67}$ Ramolissement is the French term for softening, of brain tissue in this case.

${ }^{68}$ The diarist has listed here the anatomical parts of the brain which were still healthy.

${ }^{69} \mathrm{He}$ means "methods" of applying the cupping glass.
} 
hot - scarifications he made with a scalpel. ${ }^{70}$ The recipe for the Pommade Ammoniacal is: Liq: Ammon: $3 i$ Axung: $\xi i$ Tere bem. ${ }^{71}$

Friday $27^{\text {th }}$.

Went down to Sanson this morning. As usual learnt nothing from him. Chomel lectured on Angina Pectoris. Ribail was on Setons, ${ }^{72}$ Moxas $^{73}$ \& Cauteries. Broussais on necrosis ${ }^{74}$ of the stomach. Andral commenced the subject of Phthysis today - an admirable lecture but I cannot follow his ideas completely. Must study them in the last edition of his work.

Saturday $28^{\text {th }}$.

Went to Roquet this morning - heard crepitous ${ }^{75}$ \& subcrepitous râles \& gargouillement. Man with Apoplexy Pulmonary /48v/ not dead yet. Nothing in the dead house- understood Civiale was to have an operation this morning - therefore went to Hop ${ }^{1}$. Necker. The man on whom C. operated last Saturday was ill with fever, he did not consequently examine him again today. Saw him introduce several catheters, sounds ${ }^{76} \& c$. - he does it most beautifully, most skilfully. Went into the Children's $\mathbf{H}^{1}$. But the visit was over, \& the P.M. Examination concluded. Ret ${ }^{d}$. to the Venereal Hosp ${ }^{1}$. but there was such a crowd, that after remaining a few minutes, I came away pretty well tired with my morning's amusement. Took breakf ${ }^{t}$. \& went to Ribail's - nothing particular - did not go to Gerdy's lecture.

\footnotetext{
${ }^{70}$ Cupping was a form of bleeding which involved scarifying the skin, that is making a number of superficial incisions simultaneously with an instrument called a scarifier, or, as in this case, a single incision with a lancet. Blood was drawn from the incisions by placing the glass cups, which had been held briefly over a source of heat, such as the lighted wick of an oil lamp (as in the text), over the incisions. As the air in the cups cooled and contracted the pressure on the incisions was lowered and blood flowed from them into the cups. (Hooper, Lexicon, p. 454.)

${ }^{71}$ Liq: Ammon: = liquid ammonia; Axung: = axungia; Tere bem: the meaning of this is uncertain but, since it is a pomade, it could be an instruction to rub in well.

${ }^{72}$ Seton: an artificial ulcer made under the skin by means of a seton needle threaded with silk which is repeatedly drawn through a fold of skin in such a manner as to maintain an opening for discharge from the wounded area or to keep a sinus or other cavity from healing up and so again to maintain drainage.

(Hooper, Lexicon, p. 1123.)

${ }^{73}$ Moxa: the downy covering of the dried leaves of the plant Artemisia moxa, especially as prepared in the form of a cone or cylinder for burning on the skin as a counter irritant for gout, etc. The term was also used for any substance used like moxa for burning on the skin. (Hooper, Lexicon, p. 172.)

${ }_{75}^{74}$ Necrosis: mortification, the death of tissue in the body.

${ }^{75}$ Crepitous: the correct spelling is "crepitus", but he used the typical English ending.

${ }^{76}$ Sound: an instrument used for insertion into a cavity or canal in order to ascertain whether constrictions, or foreign bodies, such as stones, are present. The instrument is so called because when it touches a stone a sound is heard. (Hooper, Lexicon, p. 1142.)
} 